\title{
УПРАВЛЕНИЕ ОБРАЗОВАТЕЛЬНОЙ СРЕДОЙ В КОНТЕКСТЕ РАЗВИТИЯ РЕГИОНАЛЬНОЙ СОЦИАЛЬНО-ЭКОНОМИЧЕСКОЙ СИСТЕМЫ
}

\author{
(c) 2021 Заборовский Денис Андреевич \\ аспирант
}

Государственный институт экономики, финансов, права и технологий, Россия, Гатчина

E-mail: denchic4@mail.ru

(C) 2021 Татур Алина Витальевна

студент, Высшая инженерно-экономическая школа

Санкт-Петербургский политехнический университет Петра Великого, Россия, Санкт-Петербург

E-mail:7156880@mail.ru

\section{(c) 2021 Конников Евгений Александрович}

кандидат экономических наук, доцент, Высшая инженерно-экономическая школа

Санкт-Петербургский политехнический университет Петра Великого, Россия, Санкт-Петербург

E-mail: konnikov.evgeniy@gmail.com

Состояние образовательной среды выступает одним из ключевых медиаторов развития региональных социально-экономических систем. Целью данного исследования является формирование обоснованной системы рекомендаций по управлению состоянием образовательной среды для целей предиктивного развития региональной социально-экономической системы. В рамках данного исследования протестирована система регрессионных уравнений для описания влияния состояния образовательной среды региона на факторы, определяющие уровень развития региональной социально-экономической системы. Также, для целей прогнозирования тенденции развития, часть моделей детально рассмотрено на мета-уровне. По результатам анализа, было установлено, что первичным фактором развития образовательной среды является уровень удовлетворённости населения компонентами образовательной среды. Данный факт определяет совокупность социальных и маркетинговых векторов развития образовательной среды региона. При этом необходимо выделить значимые временные лаги как при управлении состоянием образовательной среды региона, так и в ее влиянии на развитие социально-экономической системы. Данный факт определяет комплексность, системность и стратегическую направленность инструментов управления состоянием образовательной среды региона.

Ключевые слова: образовательная среда, социально-экономическая система, регион, уровень образования, благосостояние населения, безработица, качество жизни, уровень дохода.

В условиях динамичного процесса глобализации и цифровизации объективной действительности, все более наглядным становится дифференциация уровня развития социальноэкономических систем разного уровня. Наиболее актуальна данная проблема для региональных социально-экономических систем, так как она за счет, как природных и юридических факторов, так и за счет лингвистических факторов, существуют в условно-едином информационном поле. Открытость и наглядность данной дифференциации в первую очередь проявляется в категориях благосостояния населения. Уровень благосостояния населения является производным количественной интерпретации множе- ства факторов, а регионы России в значительной степени дифференцированы в соответствии с данными факторами. В качестве локального подтверждения можно привести результаты однофакторного дисперсионного анализа среднемесячной заработной платы, где в качестве принципа дифференциации выступает региональная принадлежность (данные взяты с 2000 по 2019 год) [1]. Значение F-критерия в данном случае составило 7,94, в то время, когда критическое значение F-критерия составляет 1,27, следовательно, дифференциация носит не случайный характер, и показатели среднемесячной номинальной начисленной заработной платы значимо варьируются в зависимости от принад- 
лежности к региону Российской Федерации.

Региональная социально-экономическая система является совокупностью множества связанных субсистем, которые могут быть условно названы средами. Одной из определяющих для региона является образовательная среда, а одним из наиболее универсальных квантификаторов состояния данной среды является уровень образования. Уровень образования дифференцирован в региональном разрезе. Результаты двухфакторного дисперсионного анализа выпуска специалистов государственными высшими учебными заведениями по регионам Российской Федерации в разрезе регионов и лет (данные взяты с 1996 по 2011) показали, что принадлежность выпуска специалистов к году обусловлена уровнем дисперсии 47,81, а принадлежность к региону - 249,14 (значения F-критерия). Данный факт свидетельствует о том, что дифференциация выпуска специалистов государственными высшими учебными заведениями в большей степени обусловлено принадлежностью к региону, а не к году. При этом именно уровень образования во многом определяет уровень развития региональной социально-экономической системы, так как потенциал развития в значительной степени определяется качеством трудовых ресурсов, который в свою очередь является следствием уровня их образования. Совокупность приведенных доводов позволяет выдвинуть гипотезу о потенциально значимом влиянии состояния образовательной среды на развитие региональной социально-экономической системы, что в свою очередь позволяет сформулировать цель - формирование обоснованной системы рекомендаций по управлению состоянием образовательной средой для целей предиктивного развития региональной социальноэкономической системы.

Изучению вопросов развития региональных социально-экономических систем, связанного с развитием образовательной среды, были посвящены работы многих исследователей. Марьям Лежава в своей работе «Влияние образования на качество жизни» говорит о том, что повышение качества образования напрямую улучшает качество жизни. Человек с более высоким уровнем IQ с большей вероятностью сможет дожить до возраста 76 лет, чем человек с более низким уровнем интеллекта [2]. Повышение уровня образования может предотвратить гибель людей от стихийных бедствий, а также положительно влияет на здоровье детей. Также Мариано Рохас в своей работе «Образование и благополучие» и И. Ю.Ложкина, Н.В.Кондрашова в своей статье «К вопросу о факторах экономического роста» утверждают, что образование положительно связано с доходом, так как более образованные люди, как правило, получают работу с высоким доходом, а доход также положительно связан с благосостоянием людей, потому что люди с высоким доходом, как правило, имеют более высокий социальный статус [3]. Что касается развития региональных социально-экономических систем под влиянием уровня образования, Н.А. Кощеева, Т. В. Зак, Н. Н. Гунько и Д. В. Шимановский, М.В.Путин в своих статьях «Развитие системы образования: условие технического прогресса и экономического роста страны», «Избыточное образование и его роль в экономическом развитии», «Влияние образования на структуру занятости молодежи», «Продолжительность жизни и экономический рост: есть ли связь между динамикой этих показателей?» уделяют этому особое внимание. Авторы подчеркивают, что экономический рост невозможен без опережающего развития уровня образования участников общественного производства [4]. Также стремление молодежи получить высшее образование является позитивным фактором, который теоретически должен привести к экономическому росту. В этих статьях также говорится о том, что экономический рост (рост ВВП какой-либо страны или увеличение ВРП некоторого региона) ведет к урбанизации, которая приводит к определенным социальным проблемам в обществе. Следовательно, рост ВВП не всегда ведет к улучшению качества жизни людей и решению социальных проблем [5]. Главной идеей авторов следующих работ: «Анализ влияния уровня образования на отдельные показатели социального развития общества», Галина Зубрицька и «Составляющие и критерии оценки уровня благосостояния: методологический аспект», И.И.Смагин, является уменьшение социальной угрозы за счет образования от общества для тех групп населения, которые не могут найти работу, предоставляя им возможность осваивать новые специальности, пройти переподготовку или дальнейшее обучение. В условиях экономических кризисов, демографических скачков и роста безработицы образование может играть роль социальностабилизирующего фактора [6]. Для того чтобы способствовать благосостоянию общества, важ- 
но разрабатывать меры и оказывать помощь лицам, принадлежащим к маргинализированным и социально незащищенным слоям населения экономически отсталым слоям общества [7].

В соответствии с приведенным теоретическим базисом можно установить, что количественной системной интерпретации связи развития образовательной среды и развития региональной социально-экономической системы на данный момент не установлено. Следовательно, данное исследование является актуальным. Методология данного исследования основана на классической методологии регрессионного и авторегрессионного анализа. Данная методология подразумевает на первом этапе определения эндогенных и экзогенных переменных будущих моделей регрессии. На основе анализа теоретического базиса можно сделать выводы о том, что на состояние образовательной среды влияет множество факторов, таких как количество обучающихся в университетах, в школах, количество выпускников с тем или иным образованием, расходы на образование в течение нескольких лет и многое другое. В то же время состояние образовательной среды может быть связано с такими индикаторами развития региональных социально-экономических систем, как заработная плата, уровень безработицы, уровень преступности и множество других. Детализация данного системного взаимодействия позволяет выделить квантификатор состояния образовательной среды региона как центроид потенциальной концептуальной модели. В качестве универсального квантификатора состояния образовательной среды региона может выступать индекс образования. Описанные ранее показатели выступают по отношению к данному центроиду как эндогенными, так и экзогенными. Данные гипотезы могут быть агрегированы в рамках единой концептуальной модели (рисуHок 1).

Проверка данной концептуальной модели и ее математическая формализация реализуется посредствам регрессионного анализа. По результатам проведения исследования была сформирована и оптимизирована система регрессионных уравнений (1).

Где:

1. $Y_{t}-$ индекс образования в конкретном регионе в период $\mathrm{t}$;

2. $X_{1 t-1}-$ численность исследователей, имеющих ученую степень в конкретном регионе в период $\mathrm{t}-1$;

3. $X_{2 t}$ - уровень грамотности в конкретном регионе в период $\mathrm{t}$;

4. $X_{3 t-3}-$ внутренние затраты на НИОКР в

$$
\left\{\begin{array}{l}
Y_{t}=-3,71+(4,98 E-06) * X_{1_{t-1}}+0,05 * X_{2_{t}}-(1,41 E-16) * X_{3_{t-3}} \\
X_{1_{t}}=1667,04+0,28 * Z_{1_{t-4}}-20,96 * Z_{2_{t-5}} \\
Z_{1_{t}}=1096+1359 * F_{1_{t-4}} \\
F_{5_{t}}=9,12-(4,63 E-05) * C_{1_{t-2}}+1.07 * C_{2_{t-2}}
\end{array}\right.
$$
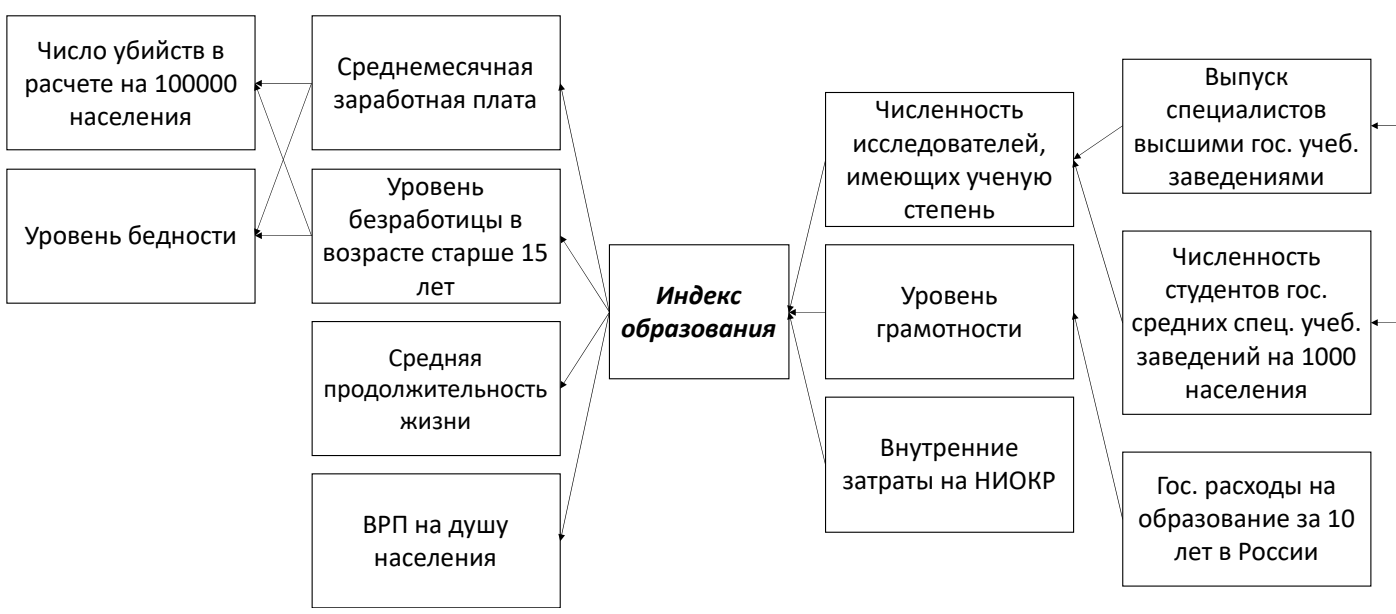

Число высших учебных гос. учреждений

Удовлетворенность населения качеством общего образования

Рисунок 1. Концептуальная модель исследования 
конкретном регионе в период $\mathrm{t}-3$;

5. $Z_{1 t-4}$ - выпуск специалистов высшими гос. учебными заведениями в конкретном регионе в период $\mathrm{t}-4$;

6. $Z_{2 t-5}-$ численность студентов гос. средних специальных учебных заведений на 1000 человек населения в конкретном регионе в период $\mathrm{t}-5$;

7. $F_{1 t-4}-$ число высших гос. учебных учреждений в конкретном регионе в период $\mathrm{t}-4$;

8. $F_{5 t}-$ уровень бедности в конкретном регионе в период $\mathrm{t}$;

9. $C_{1 t-2}-$ среднемесячная заработная плата в конкретном регионе в период $\mathrm{t}-2$;

10. $C_{2 t-2}-$ уровень безработицы в возрасте старше 15 лет в конкретном регионе в период $\mathrm{t}-2$.

Данная система регрессионных уравнений наглядно отражает лишь частичную значимость сформированной ранее концептуальной модели. На рисунке 2 приведена подтвержденная часть концептуальной модели.

Наиболее сильная связь присутствует между числом исследователей, имеющих ученую степень, и числом выпускников высших учебных государственных заведений и числом студентов государственных специальных учебных заведений, которая составляет 85\% описанной дисперсии. Обе независимые переменные имеют одинаково значимое влияние на зависимую переменную, однако они дифференцированы по направлению влияния. При увеличении выпускников высшими гос. учебными заведениями на $1 \%$, численность ученных возрастет на $2 \%$. То же самое происходит и с численностью студентов средних гос. специальных учебных заведений, только зависимая переменная будет уменьшаться на 2\%. Подобная сильная связь наблюдается между числом выпускников и числом высших государственных учебных заведений $\left(\mathrm{F}_{1}\right)$. При изменении факторного признака $\mathrm{F}_{1}$ на $1 \%$, зависимая переменная $\mathrm{Z}_{1}$ изменится на 9\%. Далее рассмотрим чуть менее сильную связь между уровнем бедности $\left(\mathrm{F}_{5}\right)$ и среднемесячной заработной платы $\left(\mathrm{C}_{1}\right)$ и уровнем безработицы $\left(\mathrm{C}_{2}\right)$. Данные факторы описывают дисперсию уровня бедности на 63\%. Наиболее сильное влияние на уровень бедности оказывает переменная $\mathrm{C}_{2}$. При ее изменении на $1 \%$, уровень бедности изменится на 0,5\%. Наиболее слабая связь, но все равно достоверная, наблюдается между индексом образования (Y) и тремя независимыми переменными: численность ученых, имеющих ученую степень $\left(\mathrm{X}_{1}\right)$, затраты на НИОКР $\left(\mathrm{X}_{3}\right)$ и уровень грамотности $\left(\mathrm{X}_{2}\right)$. Эти три фактора описывают дисперсию индекса образования на 35\%. Наиболее сильное влияние на этот признак оказывает уровень грамотности. Таким образом при изменении уровня грамотности на 1\%, индекс образования будет изменяться почти на 5\%. Оставшиеся два факторных признака оказывают крайне слабое влияние. Также имеет место одна неподтвержденная связь, но достаточно значимая - связь между индексом образования и уровнем безработицы $\left(\mathrm{C}_{2}\right)$. Несмотря на то, что индекс образования описывает всего лишь 26\% дисперсии уровня безработицы, при изменении индекса образования на 1\%, уровень безработицы будет уменьшаться почти на $11 \%$.

Так как показатели состояния образовательной среды и уровня развития региональной социально-экономической системы влияют друг на друга с определенным промежутком времени, можно отследить динамику их влияния друг на друга, рассмотрев несколько моделей сквозь года, и провести мета-исследование. В соответствии с результатами мета-анализа было установлено, что влияние индекса образования на среднемесячную заработную плату увеличива-

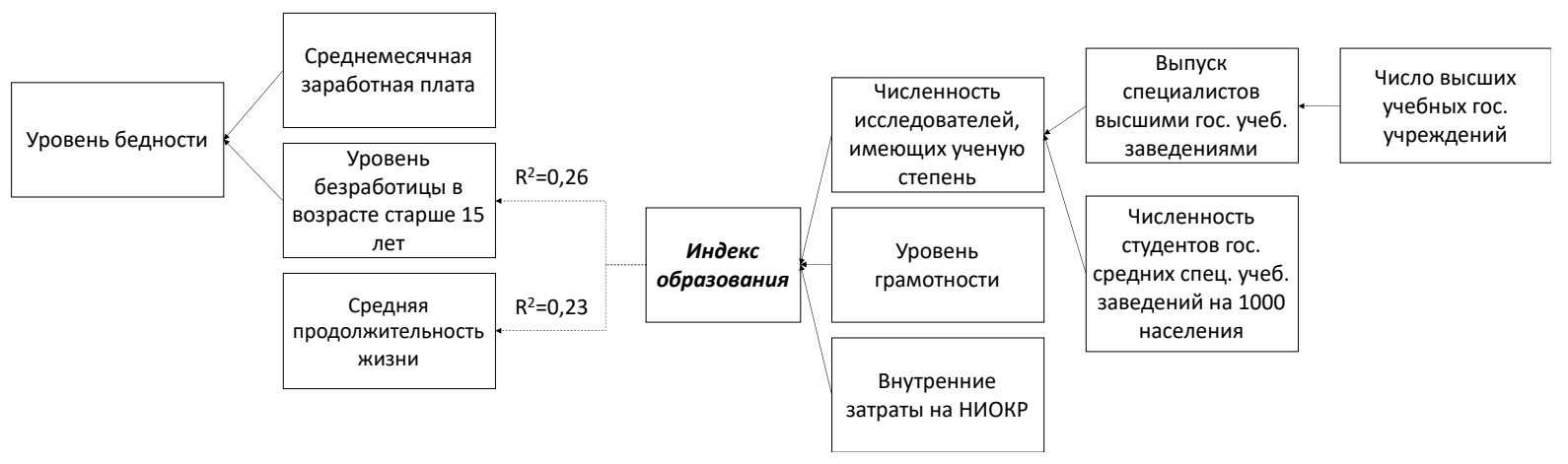

Рисунок 2. Подтверждённая концептуальная модель 
ется с годами, а на уровень безработицы - остается неизменным. Однако, связь между индексом образования и продолжительностью жизни, а также валовым региональным продуктом на душу населения с каждым годом становится слабее. Модель влияния удовлетворенности населения качеством общего образования на студентов специальных государственных учебных заведений также показала, что связь между этими двумя факторами с годами усиливается.

В завершении, рассмотрим тезисы, связанные с влиянием состояния образовательной среды на развитие региональной социальноэкономической системы. Так, экономист Марям Лежава утверждает в своих работах, что чем выше уровень образования, тем больше продолжительность жизни. В соответствии с результатами данного исследования можно дискутировать с данным утверждением, так как уровень образования не только не имеет никакой значимой связи с продолжительностью жизни, но и со временем влияние образования на продолжительность жизни только ослабевает. Что касается работ Мариано Рохас и И.Ю.Ложкина, то они в своих исследованиях раскрывают тему повышения дохода с повышением уровня образования, что в меньшей степени дискуссионно. Согласно данному исследованию, образование имеет крайне малое значение в формировании среднемесячной заработной платы, однако, с каждым годом уровень образования все больше и больше влияет на уровень доходов. В условиях современности многие работодатели принимают на работу только тех сотрудников, у которых присутствует диплом о наличии высшего образования. Зачастую, наличие высшего образования является надбавкой к заработной плате [8]. Также авторы данных научных работ говорят о том, что, при более высоком уровне образования какого-либо региона, снижается уровень безработицы соответствующего региона. Исходя из результатов данного исследования, можно утверждать, что образование занимает слишком малую долю в составе уровня безработицы, примерно около 2-ух процентов. Однако, с ростом уровня образования и профессиональной квалификации снижается вероятность потерять работу и перейти в категорию безработных, и наоборот. При этом индивид может считать, что определенная работа, несоответствующая его ожиданием, недопустима. Данный факт свидетельствует о том, что образование тесно связа- но с таким явлением как безработица, и, чем больше людей с высоким уровнем образования, тем ниже будет уровень безработицы. Согласно мета-статистике данного фактора, влияние уровня образования никак не влияет на уровень безработицы с течением времени. Такие экономисты, как Н.А.Кощеева и Д.В.Шимановский с М.В.Путиным исследовали в своих работах связь между уровнем образования и экономическим положением региона и пришли к выводу о том, что более высокий уровень образования улучшает экономическое положение региона. Однако, они также говорят о том, что рост ВРП не всегда улучшает качество жизни населения. В рамках данного исследования было установлено, что образование в среднем описывает только 7\% дисперсии валового регионального продукта на душу населения, что означает, что состояние образовательной среды региона не оказывает практически никакого влияния на формирование ВРП. Также исследовав влияние данных показателей в динамике, было установлено, что с течением времени связь между данными показателями ослабевает.

В завершении рассмотрим специфику формирования состояния образовательной среды. На индекс образования наибольшее влияние оказывает такой показатель, как уровень грамотности, что в меньшей степени справедливо для числа ученых, имеющих ученую степень, и затрат на НИОКР. Данная модель показала крайне низкую степень доверия, следствием чего во многом являются боевые действия в некоторых республиках Северо-Кавказского федерального округа 2014 года. Следствием данного факта является то, что у государства не формируется предпосылок к созданию новейших образовательных программ, снижается количество квалифицированных педагогов всех уровней образования, у обучающихся нет желания повышать свой уровень образования, так как экономическое положение региона ухудшается, а значит, снижается и заработная плата. В Ленинградской области в этом же году вышел новый закон об образовании, который повлиял на снижение уровня образования. Это может быть связано с тем, что перестраивается система образования, и возникает неопределенность требований к обучающему составу. Для целей увеличения уровня образования, и, как следствие, улучшения состояния образовательной среды, путем увеличения численности ученых, необходимо соз- 
давать новые учебные заведения, а также создавать новейшие программы обучения и условия для обучения студентов любых уровней образования, чтобы повысить удовлетворенность населения качеством общего образования. Как показывают результаты данного исследования, чем больше потенциальных студентов удовлетворены системой образования региона, тем больше из них склонны поступать в высшие учебные заведения, следствием чего является потенциальное повышение числа ученых с ученой степенью. Для целей повышения уровня удовлетворенности населения процессом обучения, необходимо усилить государственный контроль за качеством образовательных услуг, что может быть выражено в следующей совокупности инструментов управления - создание значимой материаль- ной базы, обеспечивающей процесс обучения; развитие цифровой грамотности преподавателей и обучающихся путем надлежащего и эффективного использования информационнокоммуникационных технологий; разработка эффективных учебных программ и стандартов. Таким образом, влияя на инфраструктуру учебных заведений, разрабатывая новейшие и современные учебные программы, которые будут интересно и эффективно восприниматься учащимися, строя модернизированные и усовершенствованные учебные заведения, а также осуществляя контроль над качеством образования, состояние образовательной среды региона будет значимо улучшаться, что в свою очередь приведет к развитию региональной социальноэкономической системы.

\section{Библиографический список}

1. Федеральная служба государственной статистики.- Текст: электронный // Рынок труда, занятость и заработная плата: [сайт] -URL: https://rosstat.gov.ru/labor_market_employment_salaries?print=1.

2. Lezhava, M. The impact of education on the quality of life / M. Lezhava. - Текс: непосредственный // - Berlin: Article, 2020.-C. 1-4.

3. Rojas, M. Education and Well-Being / M. Rojas.- Текст: непосредственный // Well-Being in Latin America in Human Well-Being Research and Policy Making: Book Series, 2019.- C. 125-139.

4. Кощеева, Н.А. Развитие системы образования: условие технического прогресса и экономического роста страны / Н.А. Кощеева.- Текст: непосредственный // Управление социально-экономическими системами.- Челябинск: Статья, 2010.-С. 107-110.

5. Шимановский, Д. В. Продолжительность жизни и экономический рост: есть ли всязь между динамикой этих показателей? / Д.В.Шимановский, М.В.Путин.- Текст: непосредственный // Современная экономика: проблемы и решения.-Статья, 2019.-С. 96-103.

6. Зубрицкая, Г. Г. Анализ влияния уровня образования на отдельные показатели социального развития общества / Г. Г. Зубрицкая.- Текст: непосредственный // Сборник научных трудов Харьковского национального университета Воздушных Сил.-Краков: Статья, 2018.-С. 113-118.

7. Rojas, M. Education and Well-Being / M. Rojas.- Текст: непосредственный // Well-Being in Latin America in Human Well-Being Research and Policy Making. - Book Series, 2019. - C. 125-139.

8. Gunko N. N., Impact of education on the structure of youth employment / N, Gunko N, A, Dinukova O. - Tекст: непосредственный // European Proceedings of Social and Behavioural Sciences. - Статья, 2020. - C. 874-880.

9. Rodionov, D. Relation between Russian universities and regional innovation development / D. Rodionov, D. Velichenkova // Journal of Open Innovation: Technology, Market, and Complexity._-2020._- Vol. 6. - No 4. - P. 1-26.-DOI 10.3390/joitmc6040118.

10. Заборовская, О.В. Бизнес-модели учреждений высшего образования в условиях инновационного развития региональной экономики / О.В.Заборовская, М.Г. Ковязина // Бизнес. Образование. Право.- 2015.№ 1(30). - С. 132-137.

11. Родионов, Д.Г. Рейтинг университетов как инструмент в конкурентной борьбе на мировом рынке образовательных услуг / Д. Г. Родионов, О.А. Кушнева, И.А. Рудская // Инновации. - 2013. - № 11(181). - С. 89-97.

12. Родионов, Д.Г. Международный авторитет российской высшей школы: проблемы и пути решения / Д. Г. Родионов, О.А. Кушнева, Н.А. Терентьева // Инновации. - 2013. - № 9(179). - С. 81-87.

13. Кобичева, А. М. Университет в роли инновационной корпорации / А. М. Кобичева, О. В. Калинина, Д. Г. Родионов // Российский экономический интернет-журнал. - 2019.- № 4.- С. 73. 